\title{
Imaging the Morrow A Sandstone Using Shear Wave VSP Data, Postle Field, Oklahoma
}

\author{
Naser Tamimi and Thomas L. Davis \\ Reservoir Characterization Project, Department of Geophysics, Colorado School of Mines, Golden, CO 80401, USA \\ Correspondence should be addressed to Naser Tamimi, ntamimi@mines.edu \\ Received 8 June 2012; Accepted 11 September 2012 \\ Academic Editor: Joerg Schleicher
}

Copyright ( $) 2012$ N. Tamimi and T. L. Davis. This is an open access article distributed under the Creative Commons Attribution License, which permits unrestricted use, distribution, and reproduction in any medium, provided the original work is properly cited.

\begin{abstract}
Morrow sandstones constitute important oil-producing reservoirs in the Anadarko Basin in the Mid-Continent Region of the USA. Characterization of the Morrow A sandstone reservoir in Postle Field, Texas County, Oklahoma, is challenging due to its small thickness, low acoustic impedance contrast with the surrounding Morrow shale, and lithological heterogeneity. Shear wave data have been documented as a promising solution for imaging the Morrow A sandstone. Vertical seismic profiling (VSP) offers the potential to enhance shear wave imaging of the thin heterogeneous Morrow A sandstone at Postle Field. The zero-offset VSP results confirm the advantages of shear wave over compressional wave in imaging the Morrow A sandstone. Also, the final shear wave VSP image shows that, applying the proposed processing flow, we are able to image the Morrow A sandstone where the thickness is as thin as $8.5 \mathrm{~m}$.
\end{abstract}

\section{Introduction}

Pennsylvanian upper Morrow sandstones (Figure 1) constitute major oil-producing reservoirs across southeastern Colorado, southwestern Kansas, western Oklahoma, and northern Texas. They consist of multiple-stacked lenticular sandstone bodies formed within valley-fill complexes. The Morrow A is an oil-producing sandstone mainly in Oklahoma [1-3]. In this study, we mainly focus on the Morrow A sandstone in Postle Field, Texas County, Oklahoma (Figure 2).

Compressional wave studies have been mostly used in the past for characterizing the Morrow sandstones [4-7]. Briefly, there are two main challenges with characterizing the Morrow A sandstone based on compressional data: first, the thickness of the Morrow A sandstone is below the tuning thickness $[6,8]$ and secondly, the acoustic impedance contrast between the Morrow A and the surrounding Morrow shale layer is extremely low to the point that these sandstones are acoustically transparent $[9,10]$. Dipole sonic well logs reveal the low acoustic impedance contrast between the Morrow A and overlying shale (Table 1 and Figure 3).
Singh and Davis [10] showed that the low acoustic contrast between the Morrow A sandstone and surrounding Morrow shale layer and the presence of strong multiples from shallow anhydrite layers are important challenges associated with the detection of the Morrow A sandstone in compressional data (Figure 4). Full waveform modeling [10,11] suggested that shear wave data can improve the Morrow A imaging and characterization significantly in Postle Field. Hardage et al. [12] drew the same conclusion after their study on thicker section of the Morrow sandstone using three zerooffset 9C VSP surveys. Also, a 3D VSP study using shear data addressed the advantages of shear wave in imaging of sandstone layers which have low acoustic impedance is contrast with surrounding layers [13].

Shear VSP data have characteristics which make this method a unique source of information. The advantages of VSP methods used in this study involve higher frequency, better wavefield separation, and higher signal-to-noise ratio. In this study, we expect to map the Morrow A sandstone and its variations around the VSP well. To achieve this purpose, certain processing steps and enhancements were applied that will be discussed. 
Table 1: Physical and elastic properties of the Morrow shale and the Morrow A sandstone from well log data (well HMU 24-4).

\begin{tabular}{lccc}
\hline Properties & Morrow shale & Morrow A sandstone & Change from Sh to Sst \\
\hline$V_{\mathrm{P}}(\mathrm{m} / \mathrm{sec})$ & 3335 & 3875 & $+16.21 \%$ \\
$V_{\mathrm{S}}(\mathrm{m} / \mathrm{sec})$ & 1518 & 2279 & $+50.13 \%$ \\
$V_{\mathrm{P}} / V_{\mathrm{S}}$ & 2.20 & 1.70 & $-22.59 \%$ \\
$\rho\left(\mathrm{gm} / \mathrm{cm}^{3}\right)$ & 2.57 & 2.44 & $-5.01 \%$ \\
$Z_{\mathrm{P}}$ & 8571 & 9462 & $+10.38 \%$ \\
$Z_{\mathrm{S}}$ & 3901 & 5563 & $+42.60 \%$ \\
\hline
\end{tabular}

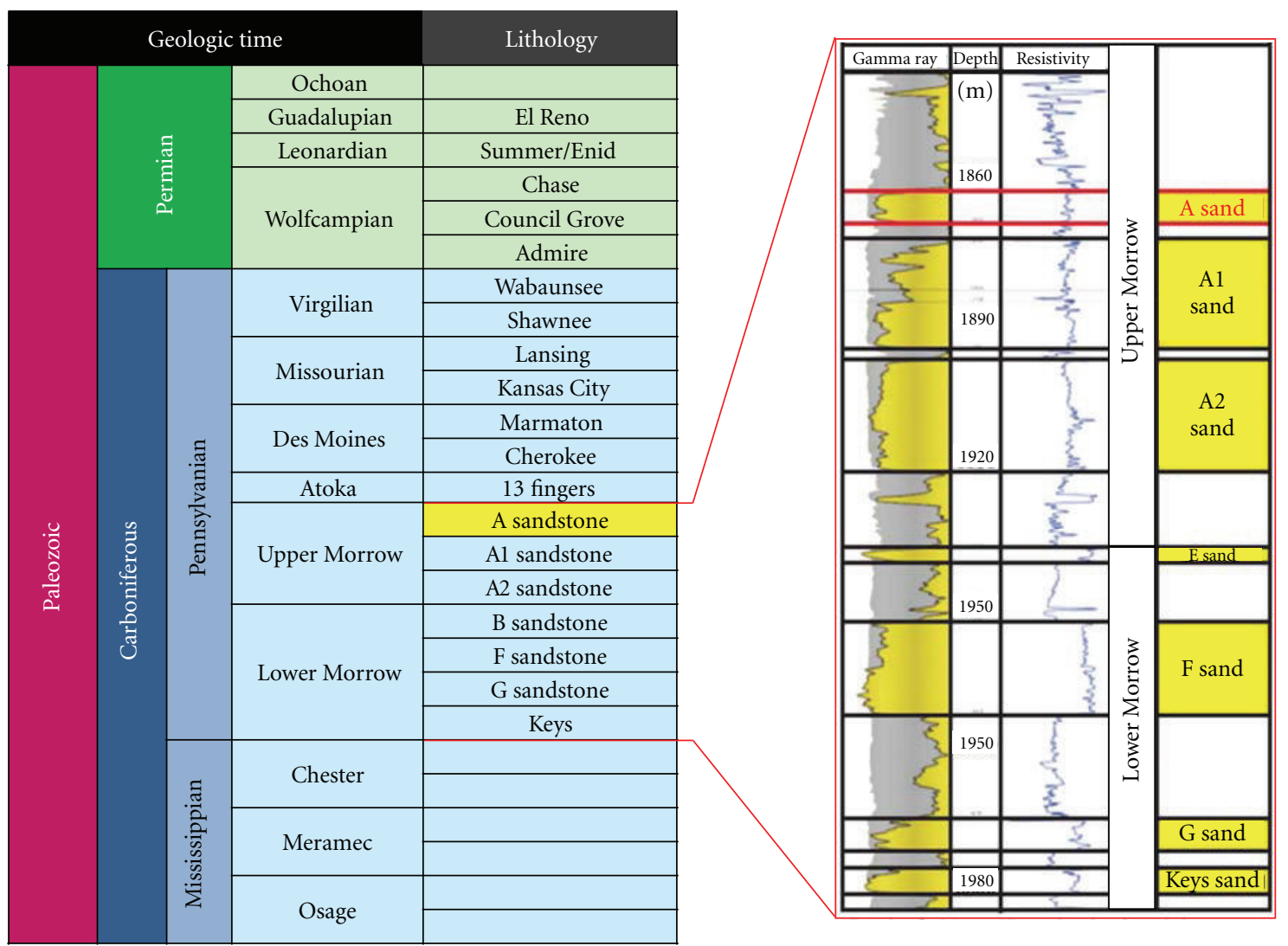

Figure 1: General stratigraphic column (left) and detailed stratigraphy column (right) show the main formations at Postle Field, Oklahoma. The Morrow A sandstone is the main oil-producing reservoir in this field. Shale layers between the Morrow sandstones are called the Morrow shales which are of important significance for characterizing heterogeneity in the reservoir.

\section{Field VSP Data}

As a part of Reservoir Characterization Project Phase XII at Colorado School of Mines, two 3D multicomponent VSP surveys were acquired from well HMU 13-2 in March and December 2008. Figures 5(a) and 5(b) demonstrate source locations and $3 \mathrm{C}$ geophone arrays in the well, respectively. For imaging purposes, we used only the March 2008 VSP survey in this paper.

The March 2008 survey was mainly acquired with horizontal vibrators, with the exception of two vertical shots: one $91 \mathrm{~m}$ to the north of the VSP well (called zero-offset data) and one $1829 \mathrm{~m}$ to the south of the VSP well (for the purpose of receiver reorientation). The horizontal vibrator truck generated two mutually orthogonal horizontal (E-W and N-S) ground motions. The geophones in the borehole were located from $933 \mathrm{~m}$ to $1818 \mathrm{~m} \mathrm{MD}$ (their depth spacing is $15 \mathrm{~m}$ ) from well head (Figure 5(b)). The last geophone was $60 \mathrm{~m}$ above the top of the Morrow A sandstone. Table 2 summarizes source and receiver parameters of the March 2008 VSP survey.

In addition to VSP data, well log and surface seismic data were used in this study. The locations of studied wells and surface seismic area are depicted in Figure 6.

\section{VSP Data Processing}

VSP processing was applied to three datasets from the March 2008 survey: zero-offset shear dataset, zero-offset 
TABLE 2: Source and receiver parameters of the March 2008 VSP survey.

\begin{tabular}{lccc}
\hline Date & Parameter & Horizontal Vib. & Vertical Vib. \\
\hline & Start frequency & $4 \mathrm{~Hz}$ & $6 \mathrm{~Hz}$ \\
& End frequency & $60 \mathrm{~Hz}$ & $100 \mathrm{~Hz}$ \\
Sarch 2008 & Start taper & $500 \mathrm{~ms}$ & $250 \mathrm{~ms}$ \\
& End taper & $500 \mathrm{~ms}$ & $250 \mathrm{~ms}$ \\
& Sweep type & Linear & $6 \mathrm{sec}$ \\
& Listen time & $8 \mathrm{sec}$ & $8 \mathrm{sec}$ \\
& Sweep length & $2 \mathrm{~ms}$ & $2 \mathrm{~ms}$ \\
\hline
\end{tabular}

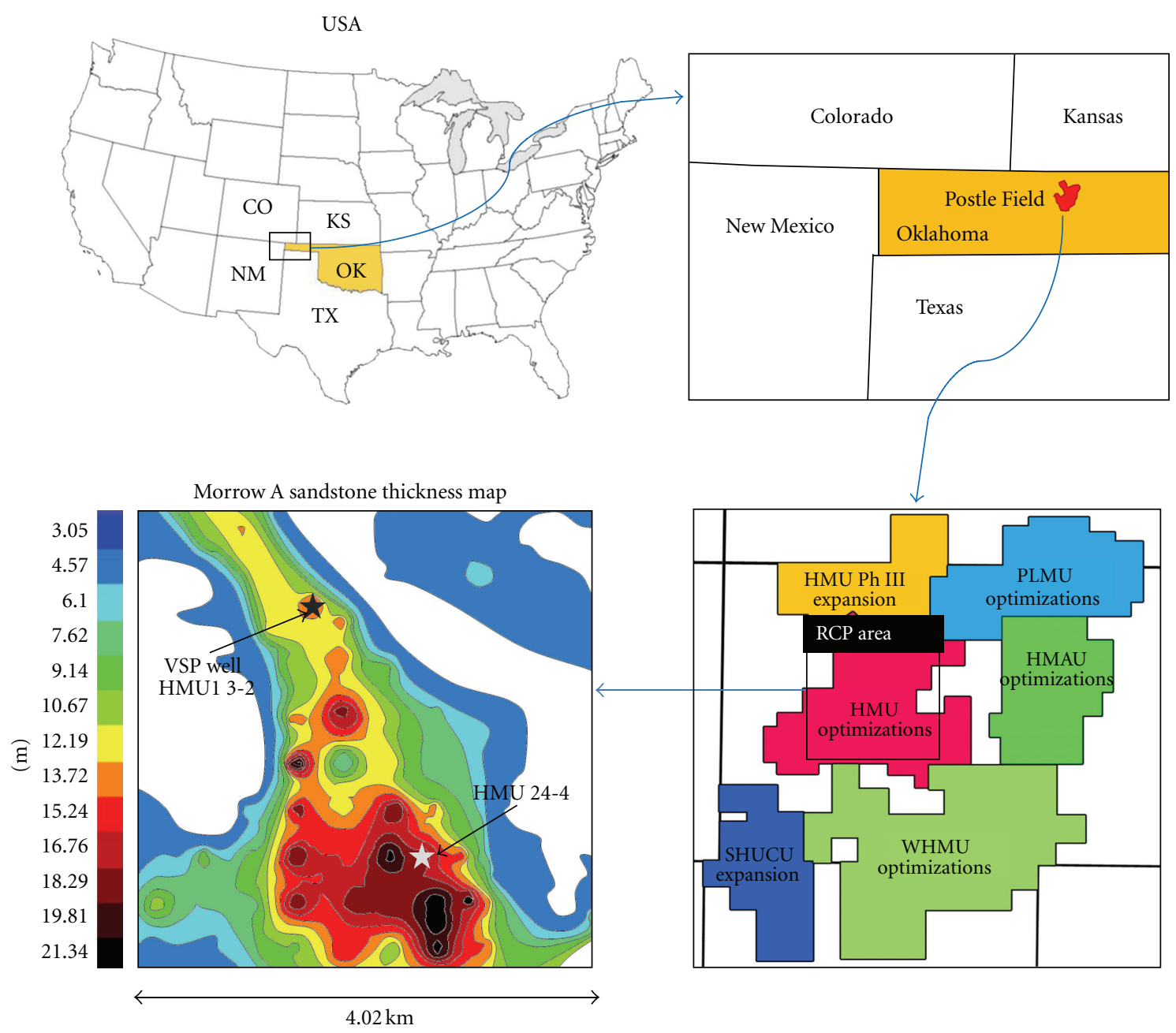

Figure 2: Postle Field is located in Texas County, Oklahoma. The RCP study area, $4.02 \mathrm{~km} \times 4.02 \mathrm{~km}$, is in the Hovey Morrow Unit (HMU). The Morrow A sandstone thickness, according to the well data, varies between $0 \mathrm{~m}$ and $21 \mathrm{~m}$, and it is thinner at the northern part of the study area. The VSP well (HMU 13-2) is located where the Morrow A is thin. The VSP data, with higher resolution than the surface seismic data, provides the opportunity of delineating the Morrow A sandstone extension.

compressional dataset, and multioffset (or 3D) shear dataset. The main goal of the proposed processing flow (Table 3 ) is to preserve the original amplitude and its variations due to lithology changes.

One of the early steps in shear wave data processing is to reorient the horizontal components of all geophones toward the constant geographical coordinate system, commonly called "Receiver Reorientation." Hodogram analysis on direct compressional wave arrivals is one of the common approaches for finding the azimuth of each different geophone components in the borehole. Modeling showed that the hodogram analysis for a source with $488 \mathrm{~m}$ offset 

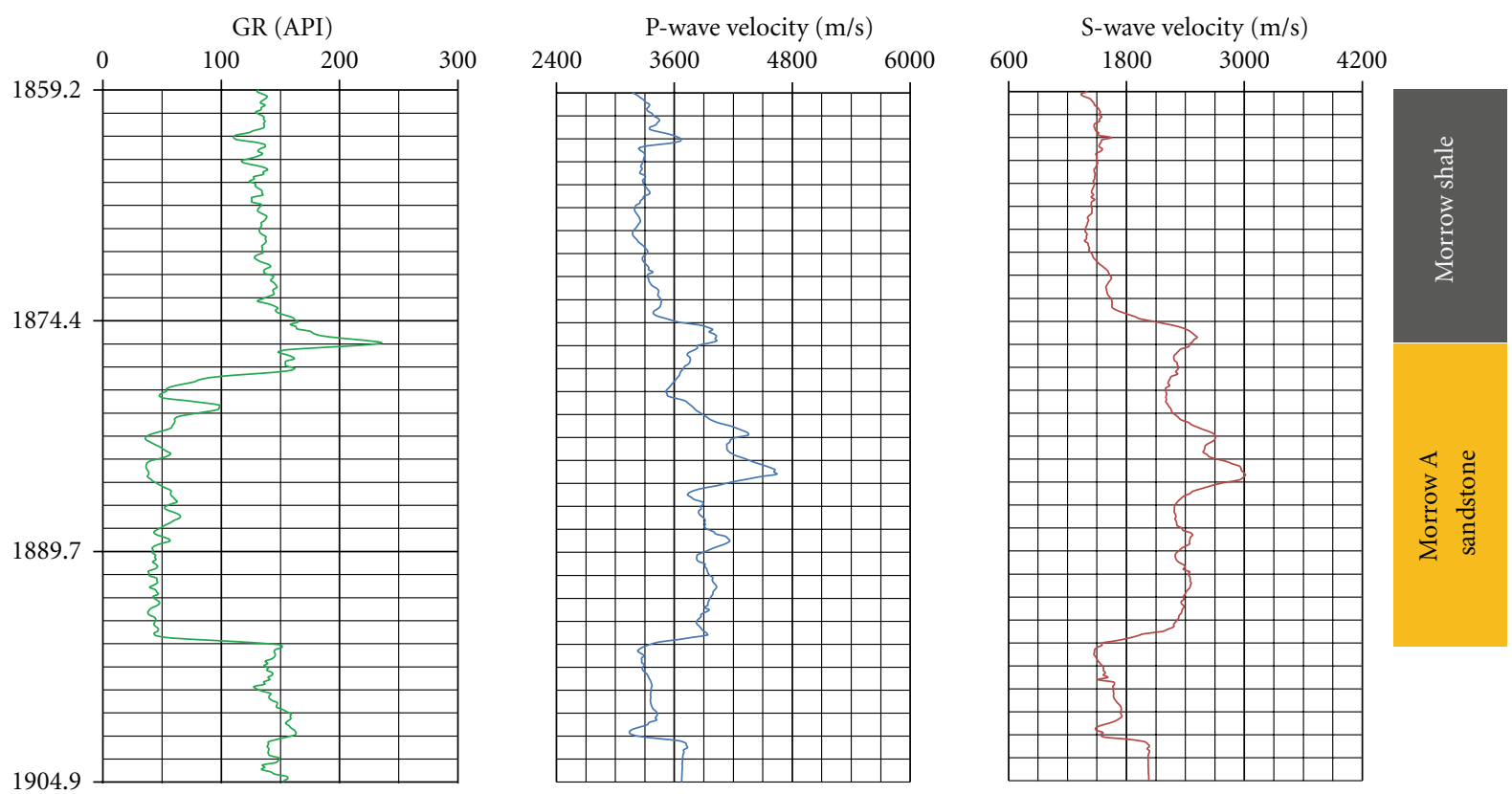

Figure 3: Gamma ray log and compressional $\left(V_{\mathrm{P}}\right)$ and shear $\left(V_{\mathrm{S}}\right)$ wave velocities at well HMU 24-4.

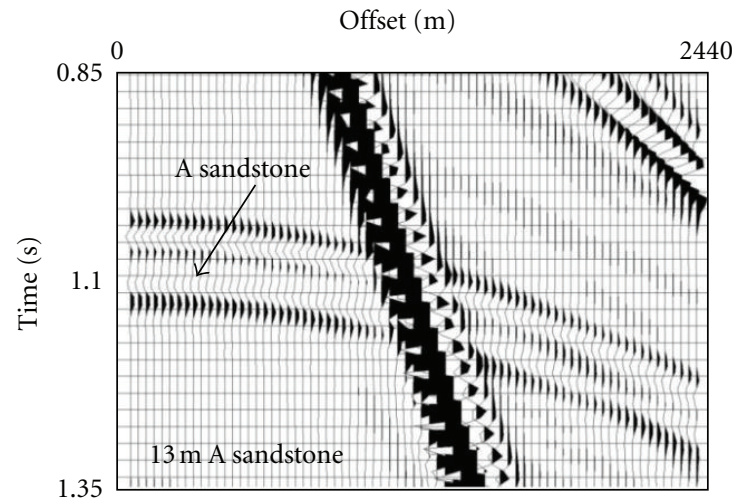

(a)

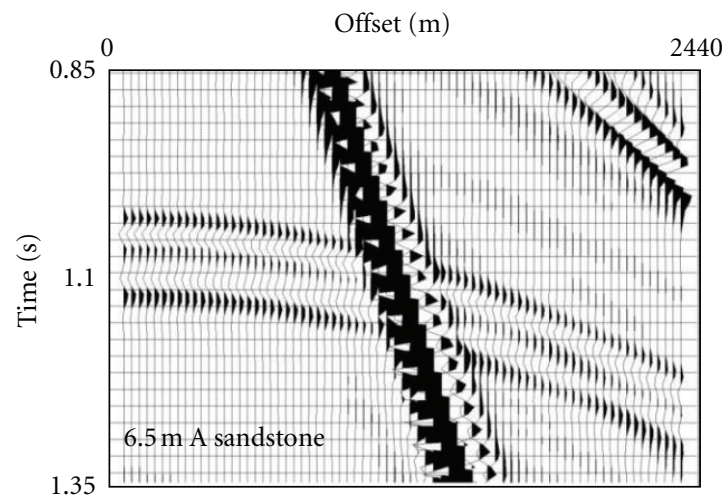

(c)

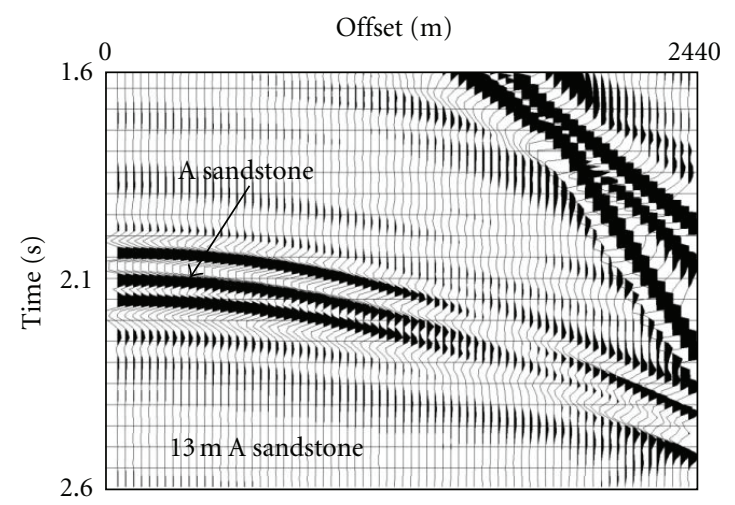

(b)

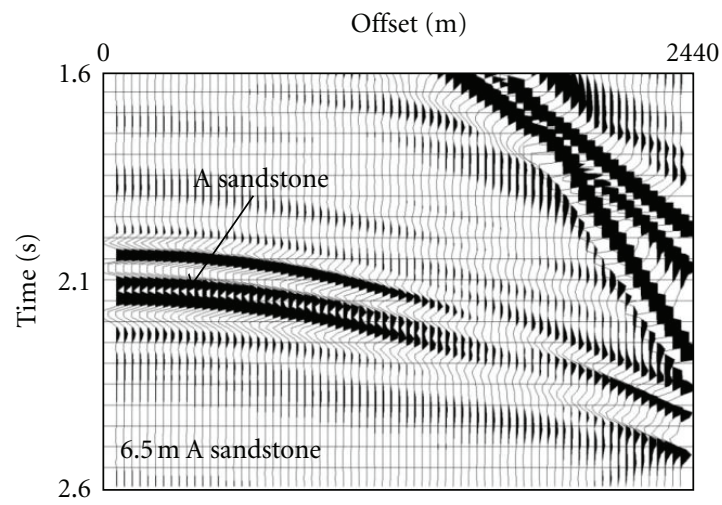

(d)

FIgURE 4: Synthetic gathers made for different thicknesses of the Morrow A sandstone in Postle Field. Compressional wave gathers (a) and (c), nonconverted shear wave gathers (b) and (d) for $13 \mathrm{~m} \mathrm{(a)} \mathrm{and} \mathrm{(b)} \mathrm{and} 6.5 \mathrm{~m} \mathrm{(c)} \mathrm{and} \mathrm{(d)} \mathrm{thicknesses} \mathrm{of} \mathrm{the} \mathrm{Morrow} \mathrm{A} \mathrm{sandstone.} \mathrm{The}$ synthetic gathers show that it is difficult to detect less than $13 \mathrm{~m}$ sandstone thickness using P-waves, because the peak doublet is absent. The nonconverted shear gather shows a distinct peak response even for $6.5 \mathrm{~m}$ of the Morrow A sandstone thickness [10]. 


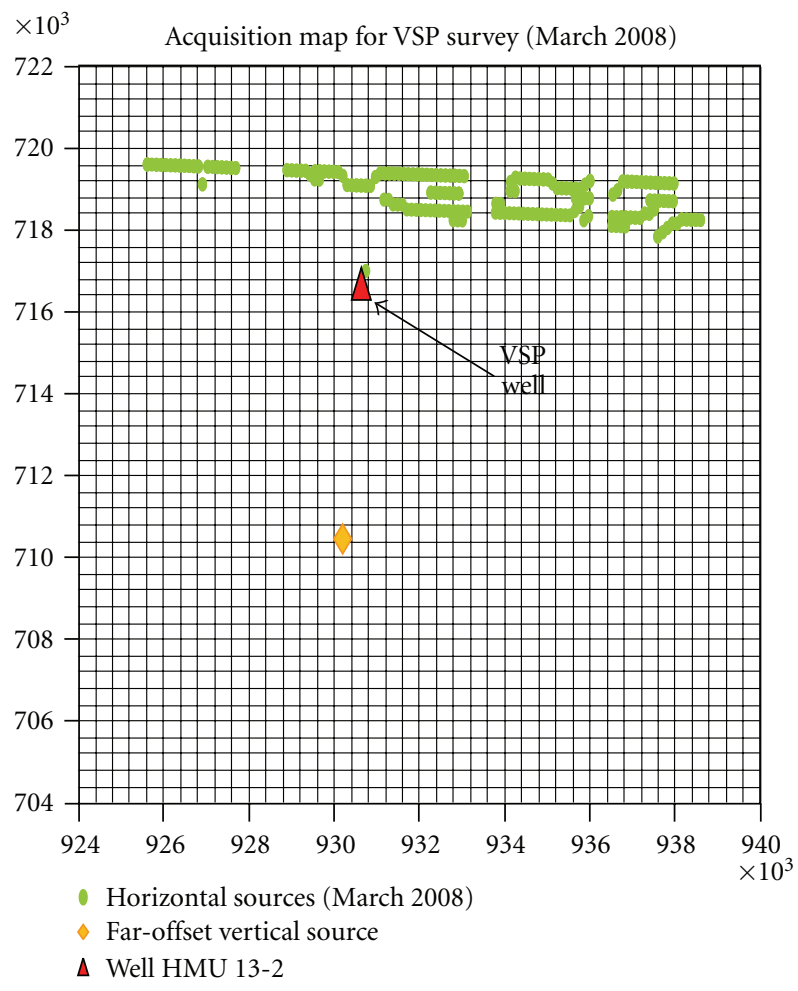

(a)

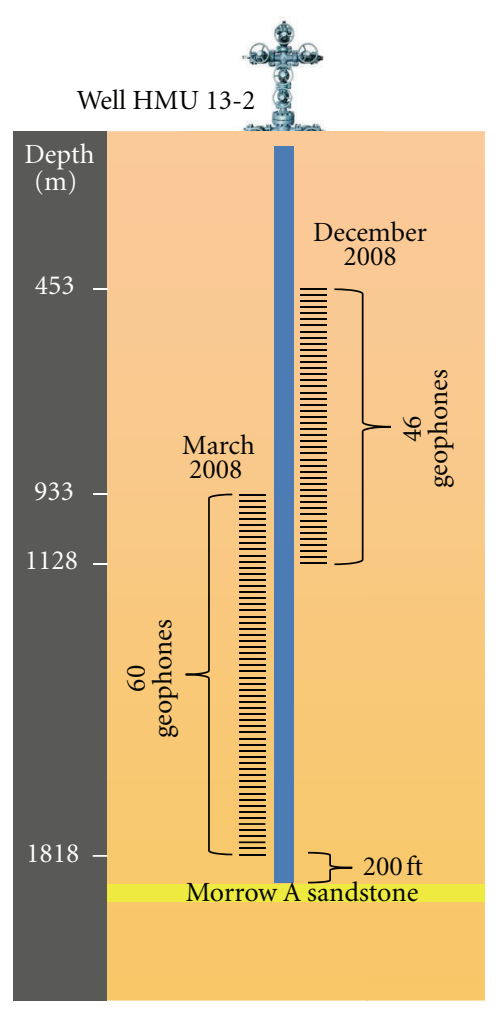

(b)

FIgure 5: (a) The March 2008 survey data were used to image the Morrow A sandstone around the borehole. The zero-offset December 2008 survey data were also used to find the natural coordinate system in the field. (b) 3C geophone array in well HMU 13-2 used for the VSP surveys acquired in March and December 2008.

introduces up to $5 \mathrm{deg}$ error in estimation of receiver azimuth. The error is expected to increase for more complex geological structures and noisy data. To reduce the uncertainty of the hodogram analysis, usually a number of shot gathers are analyzed. Since we had only one far-offset vertical source in our dataset, the error in the hodogram analysis and the receiver reorientation could have been considerable. Amplitude and time variations of the first shear wave arrivals in reoriented data (Figure 8(a)), using hodogram analysis of only the vertical source, confirmed the uncertainty in estimation of receivers azimuth. Uncertainty in receiver reorientation can diminish weak reflections from the reservoir or make invalid amplitude variations in the final VSP image. Because of this reason, we modified the receiver reorientation process by utilizing two more analyses: (1) hodogram analysis of compressional wave arrivals from a few horizontal vibrators and (2) 3C amplitude analysis. Hodogram analysis of the compressional wave generated by horizontal sources improved receiver reorientation results for some shallow geophones. Besides the mentioned methods, 3C amplitude analysis was done on the data which improved the results. In this approach, we rotated all three components of each geophone in a 3D half space and the RMS amplitude maps of the first arrivals of compressional and shear waves were projected onto two separate stereonets (Figure 7). The amplitude maps from 3C amplitude analysis are supposed to show the direction of maximum direct compressional and shear wave energy in 3D space around the receivers. Therefore, accurate receiver reorientation should lead to the similar amplitude pattern on all geophones. Using this approach, some residual reorientation angles were calculated. Interpretation of the projected amplitude maps, in addition to previous hodogram analyses, provided more accurate rotation angle for aligning receivers (Figure 8(b)).

After the receiver reorientation, based on the polarity of the shear wave direct arrivals, the data polarity for different shots was fixed. Different receivers were rotated to the local coordinate system (radial-transverse), and then they were tilted in the direction of direct shear wave to maximize shear wave energy on the horizontal components. Many of the compressional wave arrivals and reflections disappeared on the horizontal components after this step.

\section{Shear Wave Splitting}

When a shear wave enters an anisotropic medium, it splits into two polarized shear waves that travel with different velocities $[14,15]$. Shear wave splitting is an important phenomenon that requires attention during shear wave data processing and interpretation. Typically, when the medium is azimuthally anisotropic, shear wave data will be processed and presented in two modes: fast shear wave data $\left(S_{1}\right)$ and slow shear wave data $\left(S_{2}\right)$. Finding the fast and slow 
TABLE 3: The proposed flow for processing the zero-offset and multioffset VSP datasets. A few processing techniques were introduced to preserve the original amplitude content of the data. (A) The zero-offset shear wave dataset, (B) the zero-offset compressional dataset, and (C) the multioffset shear wave dataset.

\begin{tabular}{|c|c|c|c|}
\hline Processing steps & (A) & (B) & (C) \\
\hline (1) Input VSP data and loading geometry on data headers & $\mathrm{X}$ & $\mathrm{X}$ & $\mathrm{X}$ \\
\hline (2) Vibroseis sweep correlation and removing high frequency noises. & $\mathrm{X}$ & $\mathrm{X}$ & $\mathrm{x}$ \\
\hline (3) $P$-wave first break arrivals & & $\mathrm{X}$ & $\mathrm{x}$ \\
\hline \multicolumn{4}{|l|}{ (4) Hodogram analysis on $P$-wave arrivals from a far vertical source } \\
\hline (5) Hodogram analysis on $P$-wave arrivals from a few horizontal sources & & & $\mathrm{x}$ \\
\hline (6) $3 \mathrm{C}$ amplitude analysis & $\mathrm{x}$ & & $\mathrm{x}$ \\
\hline (7) Receiver reorientation & $\mathrm{x}$ & & $\mathrm{x}$ \\
\hline (8) Fixing vibrator polarity & $\mathrm{x}$ & & $\mathrm{x}$ \\
\hline (9) Rotating data to the local coordinate system (radial-transverse) & & & $\mathrm{X}$ \\
\hline (10) Calculating inclination of transmitted shear wave for each receiver & & & $\mathrm{X}$ \\
\hline (11) Tilting each receiver based on calculated inclination & & & $\mathrm{x}$ \\
\hline (12) $2 \mathrm{C}$ rotation analysis & $\mathrm{X}$ & & \\
\hline (13) Alford rotation analysis & & & $\mathrm{X}$ \\
\hline (14) Rotating data to the natural coordinate system & & & $\mathrm{x}$ \\
\hline (15) Creating velocity model and true amplitude recovery & $\mathrm{x}$ & $\mathrm{X}$ & $\mathrm{x}$ \\
\hline (16) Applying median filter to isolate upgoing shear wave & & & $\mathrm{x}$ \\
\hline (17) Applying dual median filter* to isolate desirable upgoing wave & $\mathrm{x}$ & $\mathrm{X}$ & \\
\hline (18) Applying deconvolution filter on upgoing waves using downgoing waves & $\mathrm{x}$ & $\mathrm{X}$ & \\
\hline (19) Aligning upgoing events and making corridor stack & $\mathrm{x}$ & $\mathrm{X}$ & \\
\hline (20) Normalizing amplitude for different shots & & & $\mathrm{X}$ \\
\hline (21) Applying VSP-CDP transformation on 2D VSP lines & & & $\mathrm{X}$ \\
\hline
\end{tabular}

* Dual median filter is explained in Section 3.

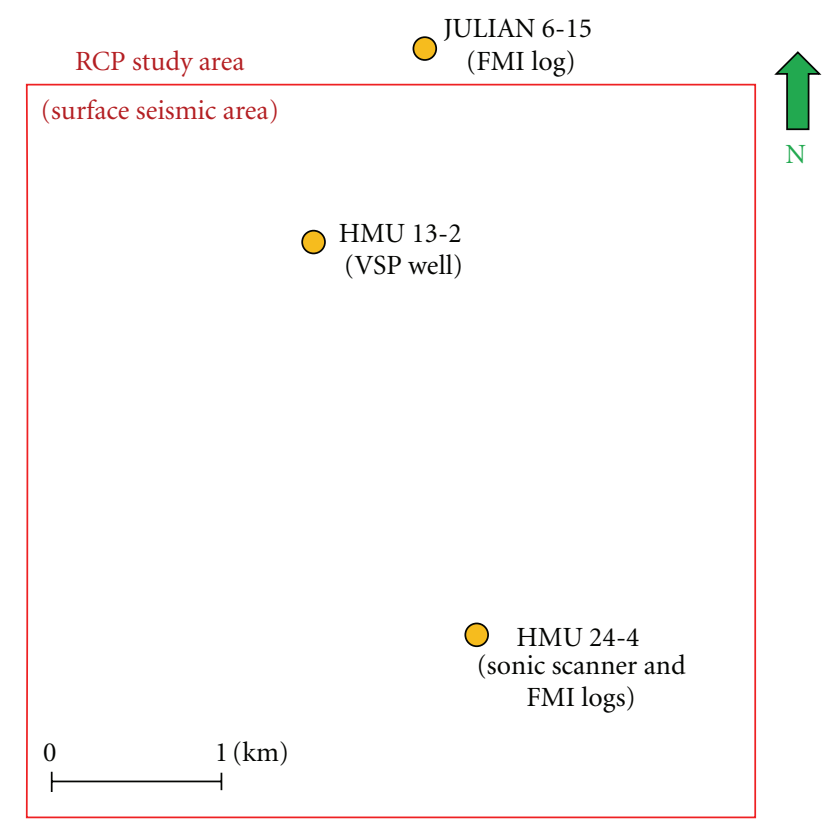

Figure 6: Map shows locations of the studied wells and the 3D 9C surface seismic area at Postle Field.

shear wave polarization directions (or the natural coordinate system) and their spatial and temporal variations has a significant impact on the quality of the final shear wave image. Therefore, information from different tools gives us better insight about the reason for shear wave splitting, the polarization directions of fast and slow shear waves, and their temporal and spatial variations. Here, to show the importance of contributing different sources of information, we analyzed four different tools: full waveform sonic log (sonic scanner), image logs (FMI), multicomponent zerooffset VSP data, and multi-offset VSP data.

Slowness dispersion analysis (Figure 9(a)) on sonic scanner data from well HMU 24-4 (Figure 6) shows that the anisotropy in the study area, especially at the reservoir level, is mostly stress-induced anisotropy [16, 17]. In addition, the sonic scanner data suggest that the fast shear wave polarization direction is $126 \mathrm{deg}$ (all the angles in this analysis are respect to north) at the reservoir level and $108 \mathrm{deg}$ for the entire logged section (Figure 9(b)).

Since the origin of anisotropy in the field is presumed to be stress-induced anisotropy, fast and slow shear wave polarization directions should match maximum and minimum horizontal stress directions at the field. Drillinginduced fractures usually form in the direction of maximum horizontal stress [18], and they are detectable on microimaging logs (e.g., FMI logs). Figure 10 depicts the direction of some drilling-induced fractures in well HMU 24-4 and JULIAN 6-15 (Figure 6). Most of the drilling-induced fractures formed around $125 \mathrm{deg}$ which is very close to the sonic scanner results. Although both image and sonic scanner logs are useful tools in determining the anisotropy 


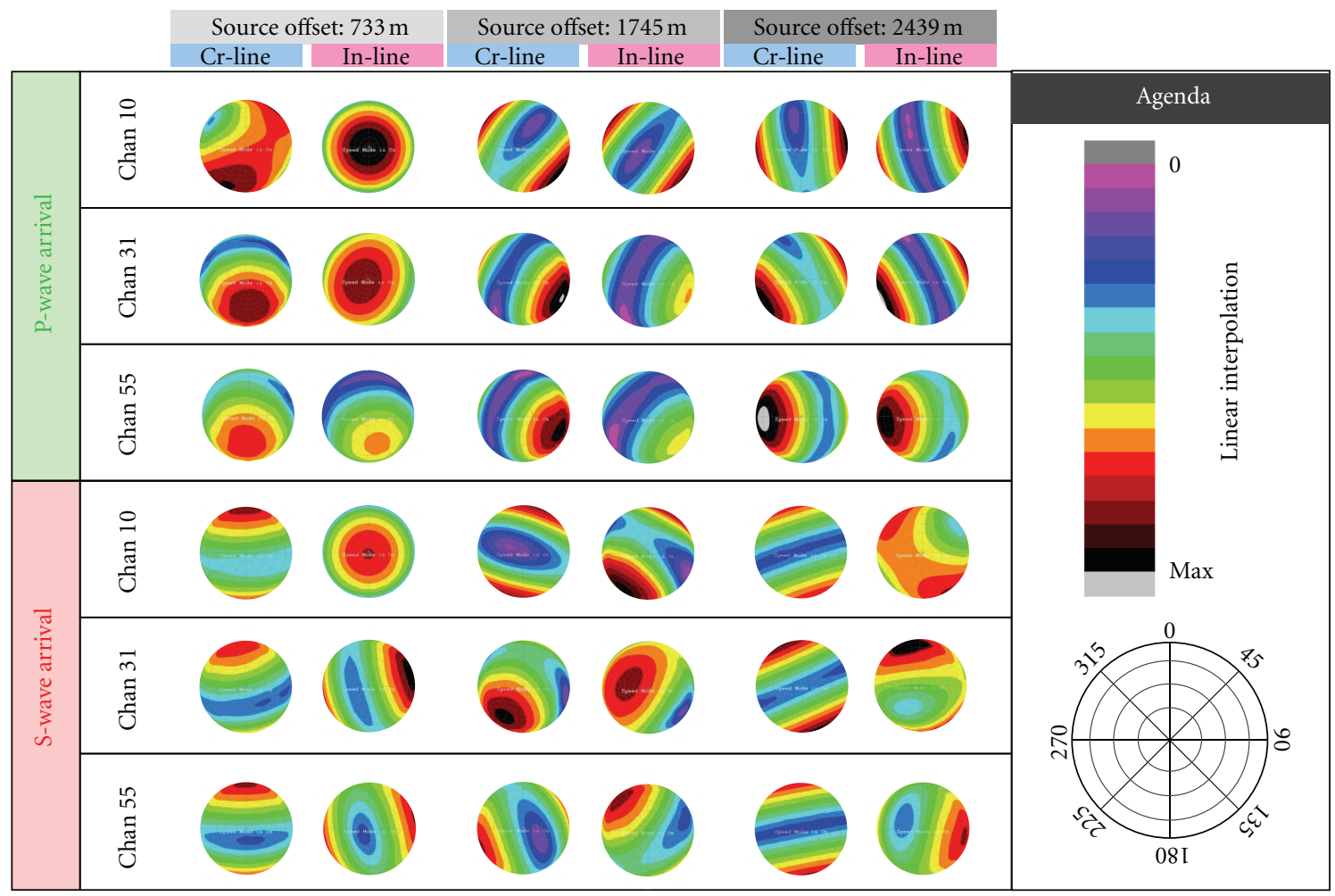

FIgURE 7: Projection of first-arrival compressional and shear wave amplitudes for H1 component of three different geophones (channel 10,31 , and 55) and three different horizontal-vibrator source offsets ( $733 \mathrm{~m}, 1745 \mathrm{~m}$, and $2439 \mathrm{~m}$ ). The pattern of these maps helped us to estimate the azimuth of each geophone component in the borehole. The results of the $3 \mathrm{C}$ amplitude analysis, in addition to the vertical and horizontal sources hodogram analyses, improved the receiver reorientation process.

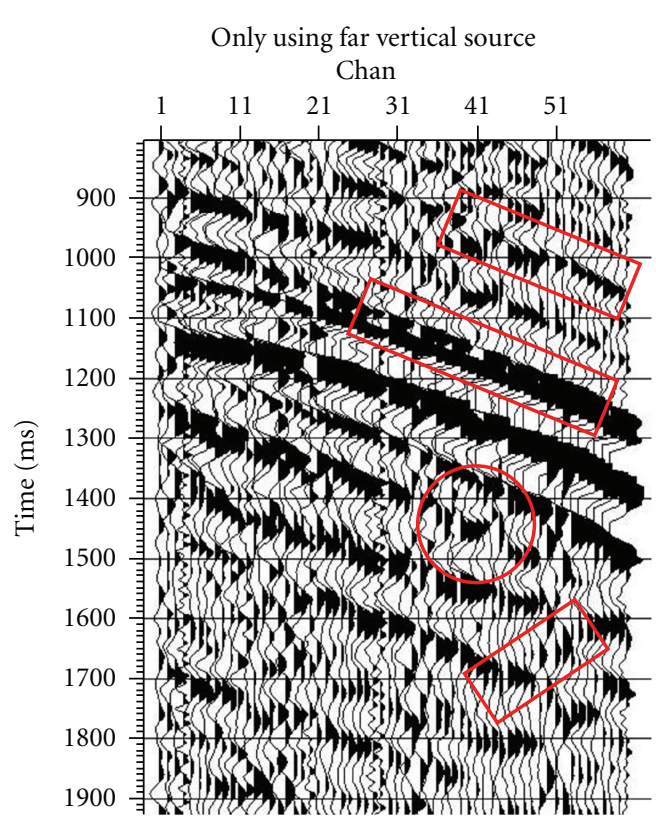

(a)

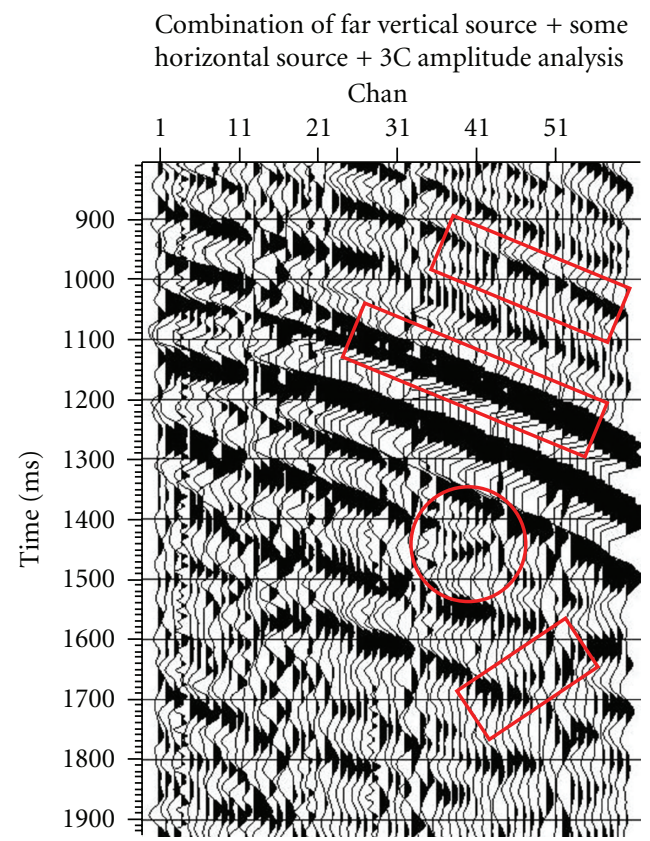

(b)

FIGURE 8: (a) shows a shear wave VSP shot gather after reorienting receivers based on the compressional wave hodogram analysis of only the far-offset vertical source. (b) depicts the same shot gather after utilizing three methods (i.e., compressional wave hodogram analysis of the far-offset vertical source, compressional wave hodogram analysis of a few horizontal sources, and the 3C amplitude analysis). Utilizing three methods in the receiver reorientation process caused remarkable improvements (note the red boxes and circles). 


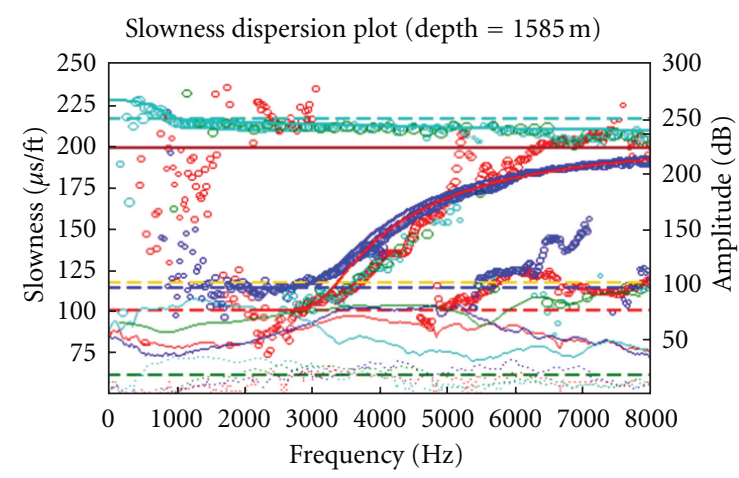

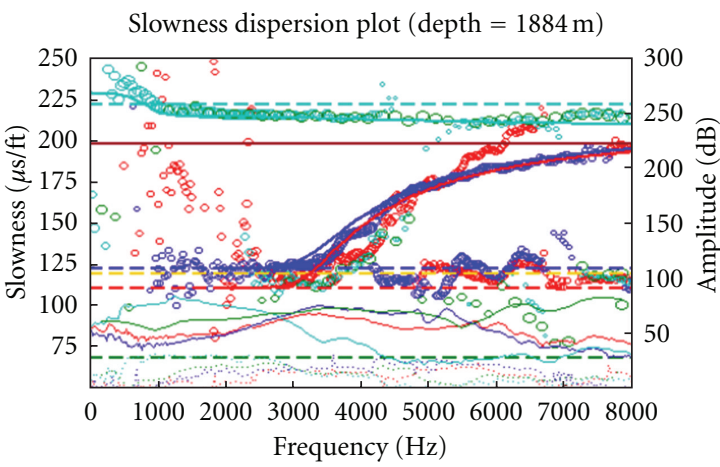

Slow flexural wave Fast flexural wave Stoneley wave

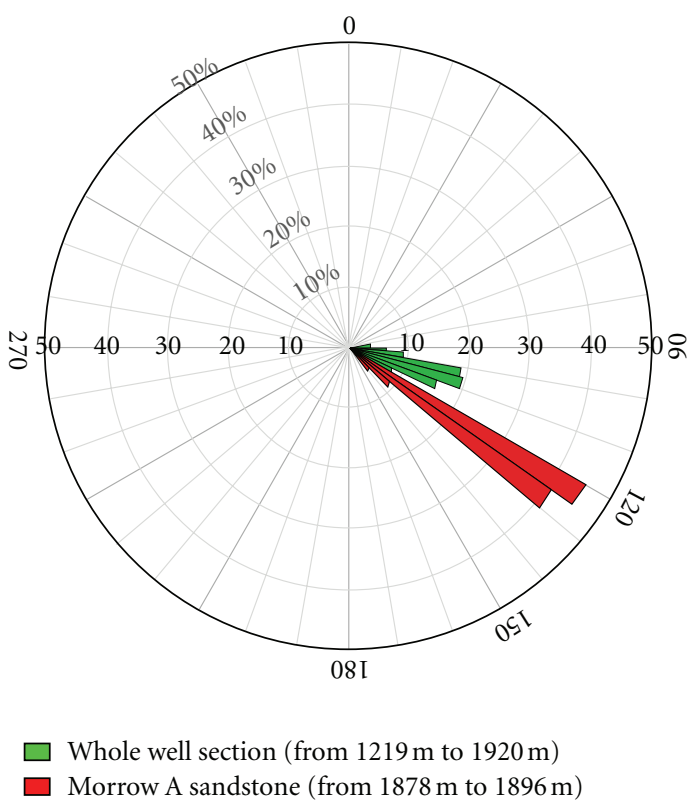

(b)

Figure 9: (a) Two flexural wave dispersion curves measured in well HMU 24-4. The red and blue circles represent fast and slow flexural waves, respectively. The cyan circles showes the Stoneley wave. The crossover pattern between the fast and slow dispersion curves show that the type of the anisotropy is stress-induced anisotropy. (b) The sonic scanner data suggest that the fast shear wave polarization azimuth is $126 \mathrm{deg}$ at the reservoir level (from $1878 \mathrm{~m}$ to $1896 \mathrm{~m}$ ) and 108 deg for the entire logged section (from $1219 \mathrm{~m}$ to $1896 \mathrm{~m}$ ).

direction, both datasets are limited to the deep part of the well. In addition, the radius of investigation of these sources of information is limited to the vicinity of the VSP well. To find the azimuthal anisotropy direction at shallower layers and also away from the borehole, we did a comprehensive study on the shear wave VSP data.

The other source of information for determining the azimuthal anisotropy direction is zero-offset shear VSP data. There are two available zero-offset shear VSP datasets in well HMU 13-2: the March 2008 and December 2008 data. The geophones were located in the borehole from $933 \mathrm{~m}$ to $1818 \mathrm{~m}$ MD in March 2008 survey and from $453 \mathrm{~m}$ to $1128 \mathrm{~m}$ MD in the December 2008 survey (Figure 5). The significant depth spread helps to follow the azimuthal anisotropy direction from shallow layers to deep layers. The zero-offset VSP data (March 2008 data) were acquired using a horizontal vibrator that made shear waves polarized in only the E$\mathrm{W}$ direction. Because of the single source polarization, 2C rotation analysis [19] was used to estimate the polarization directions of fast and slow shear waves (Figure 11(c)). The second zero-offset VSP data, December 2008, were acquired using one vibrator that made mutual shear wave motion in the E-W and N-S directions. These crossed-dipole sources enabled us to apply Alford rotation analysis [20] to this data. The direct application of Alford rotation analysis is to find the natural polarization direction through a mathematical operation, assuming that the two split shear waves are orthogonally polarized and the anisotropy direction in the subsurface remains constant with depth [21]. The data were rotated from $-90 \mathrm{deg}$ to $+90 \mathrm{deg}$ ( $10 \mathrm{deg}$ angle increment), and the RMS amplitude was calculated using a $200 \mathrm{~ms}$ time window around the first arrivals. Using (1), the final map (Figure 11(b)) was constructed to point out where the diagonal components (i.e., S11 and S22) had more energy than off-diagonal components (i.e., S12 and S21):

$$
\text { Relative RMS Amplitude Map }=\frac{\operatorname{RMS}(\mathrm{S} 11)+\mathrm{RMS}(\mathrm{S} 22)}{\operatorname{RMS}(\mathrm{S} 12)+\operatorname{RMS}(\mathrm{S} 21)}
$$

On average, the March 2008 and December 2008 surveys suggested 134 deg as the fast shear wave polarization direction.

To understand spatial variation of the S11 polarization direction in the field, multioffset VSP data, using Alford 


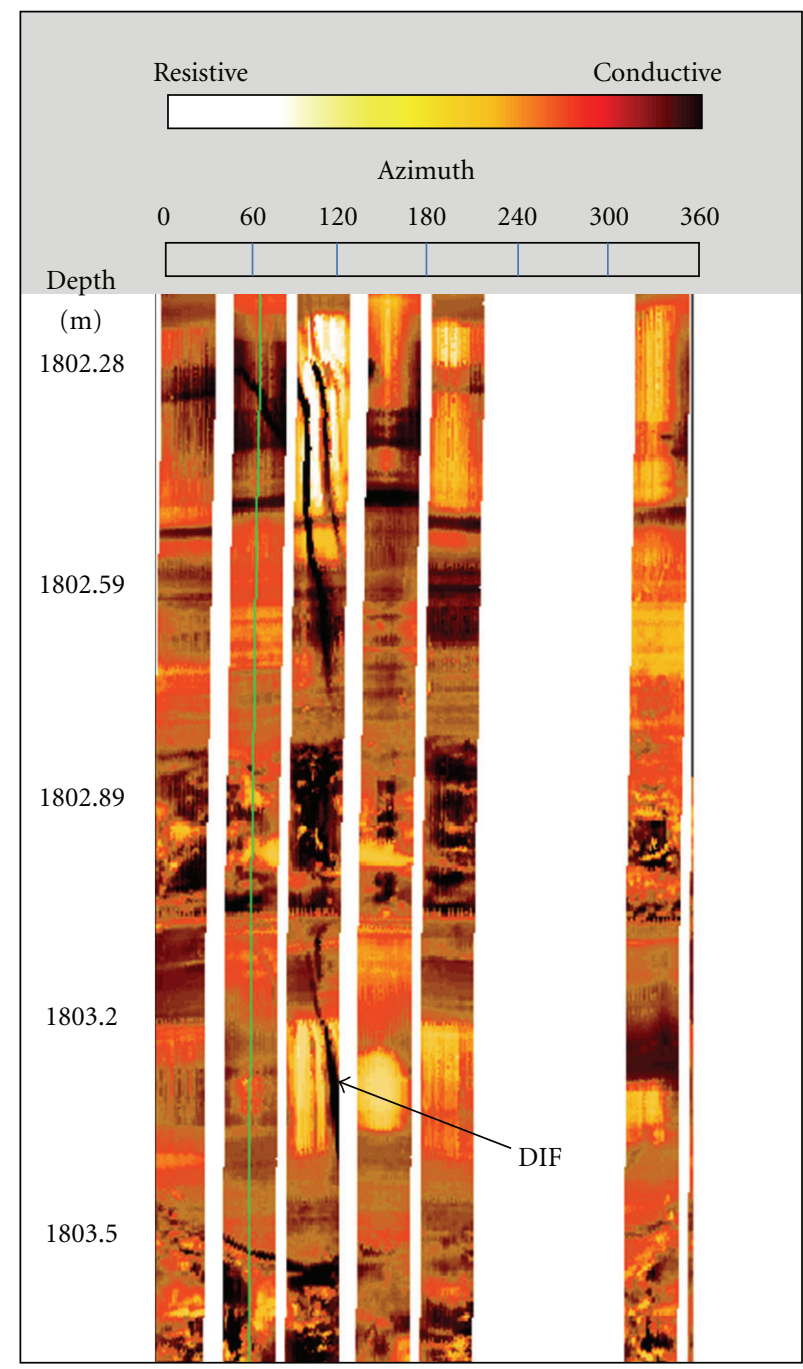

(a)

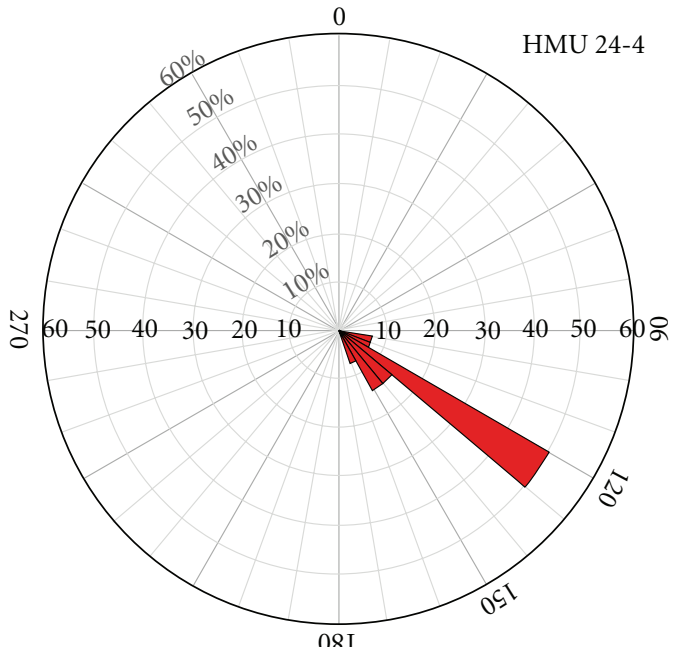

(b)

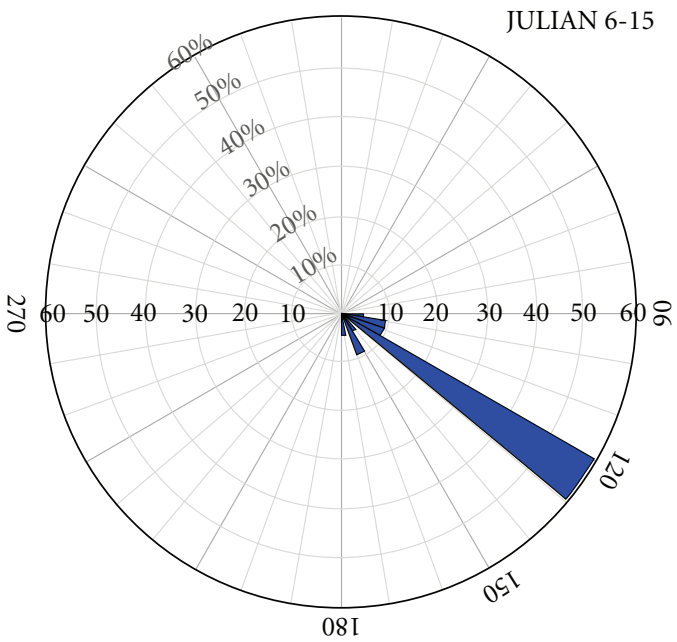

(c)

FIGURE 10: Drilling-induced fractures form in a drilled borehole in direction of the maximum horizontal stress. FMI logs could depict drilling-induced fractures on borehole wall clearly. (a) represents a part of the FMI log from the well HMU 24-4. The azimuth of the induced-drilling fractures (the high conductive vertical features) on the borehole wall was picked for two wells (HMU 24-4 and JULIAN 6-15). (b) and (c) show the azimuth of the drilling-induced fractures in the wells.

rotation analysis, were analyzed. Alford rotation analysis on multioffset VSP data (i.e., near-offset, mid-offset, and faroffset data) depicts that the fast shear wave polarization direction is approximately $138 \mathrm{deg}$ (Figure 12). Similar to the zero-offset VSP results, multioffset VSP data show that the fast shear wave polarization direction does not change significantly with depth.

Analyzing the anisotropy direction using different tools (Figure 13) suggests a $30 \mathrm{deg}$ change (from $108 \mathrm{deg}$ to $138 \mathrm{deg}$ ) that may happen because of factors such as different radius of investigation, difference in measurement frequency, complex heterogeneity of the reservoir and overlying layers, among others. A discussion of these factors is outside the scope of this paper, but the data exhibited in Figure 13 indicated that analysis of different sources of information is required to understand azimuthal anisotropy.

\section{Wavefield Separation and Imaging}

Wavefield separation was the next step in the VSP processing flow. Generally, different wave types can be recognized in VSP data better and more accurately than in surface seismic data. Because of this ease of recognition, we are usually able to effectively filter undesirable waves from VSP data. Because VSP data in Postle Field will be used to image details inside the sand channels (e.g., braid bars and channel boundaries) around the borehole, we need to preserve discontinuities in the data. Median filtering offers the unique ability to preserve discontinuities in data without smearing discontinuities [22]. Although the median filter preserves discontinuities in the data, it diminishes some weak upgoing waves and introduces high frequency noise where upgoing waves interfere with strong downgoing waves. Because some 


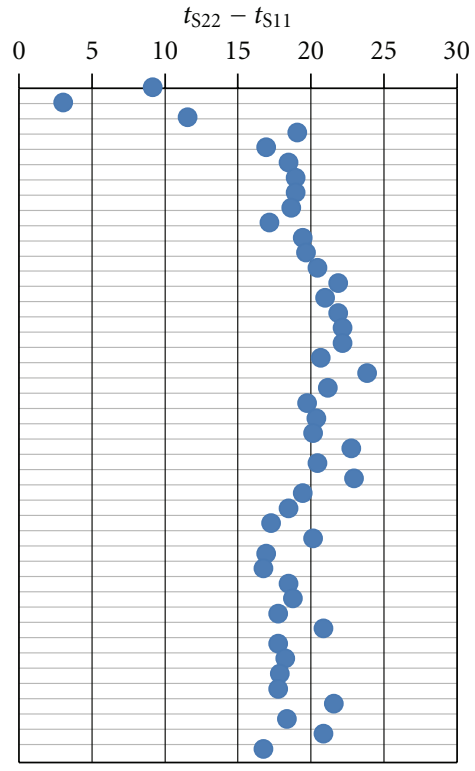

(a)

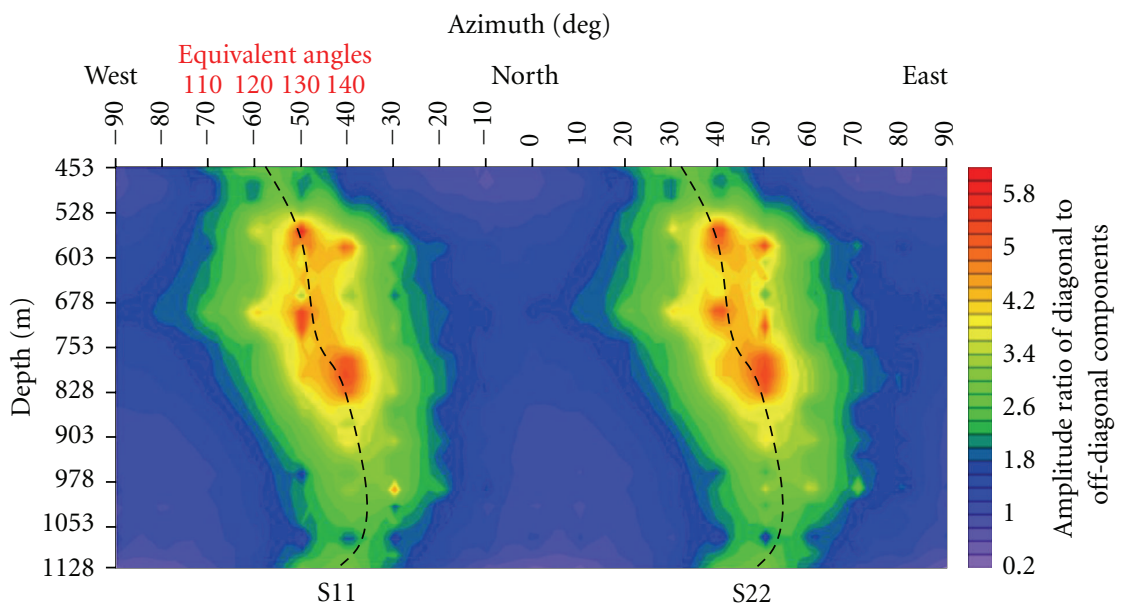

(b)

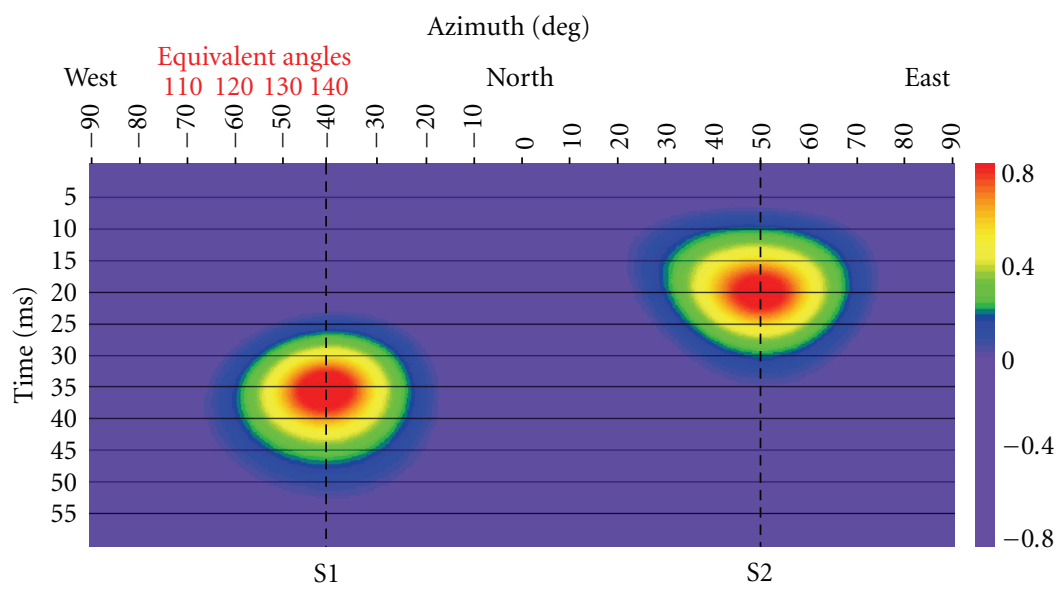

(c)

Figure 11: (a) depicts time difference between the fast and slow shear wave arrivals from the December 2008 zero-offset dataset. Alford rotation analysis (using (1) as criterion) on the December 2008 zero-offset VSP data (b) and 2C rotation analysis on the March 2008 zero offset VSP data (c) suggest that the fast shear wave polarization direction is approximately $134 \mathrm{deg}$.

geophones are close to the Morrow A sandstone, reflections (upgoing waves) from this horizon are covered by strong direct arrivals and their multiples (downgoing waves). As expected, the quality of the separated upgoing waves in the interference area is affected by the median filter and the wavefield separation process. To overcome this issue, synthetic zero-offset VSP data were built, and different parameters and approaches for wavefield separation were examined using different median filters.

In one approach, upgoing waves were aligned and they were separated using a median filter. The quality of these separated upgoing waves was not good, but after stacking this result with the separated upgoing waves using the common approach (i.e., removing downgoing waves from data), we obtained a higher signal-to-noise ratio and preserved weak reflections better (Figure 14). We called this method "Dual
Median Filtering." Because the method is adapted for zerooffset VSP data, we applied it to only the zero-offset VSP datasets. The multioffset VSP dataset was filtered by using a common median filtering. F-K filtering is another popular method for separating different wavefields but, due to the high level of noise in the data, discriminating different wavefields in the F-K domain is challenging. Also, F-K filtering cannot preserve sharp discontinuities in the data. After wavefield separation, the downgoing waves were used for making a deconvolution filter. Corridor stacks were made of the zero-offset compressional and shear wave datasets after applying the deconvolution filter (Figure 15).

VSP migration and VSP-CDP transformation are two common approaches for final VSP imaging. Lack of data fold in our VSP survey makes VSP migration method ineffective. An alternative for VSP migration in this case is the VSP-CDP 

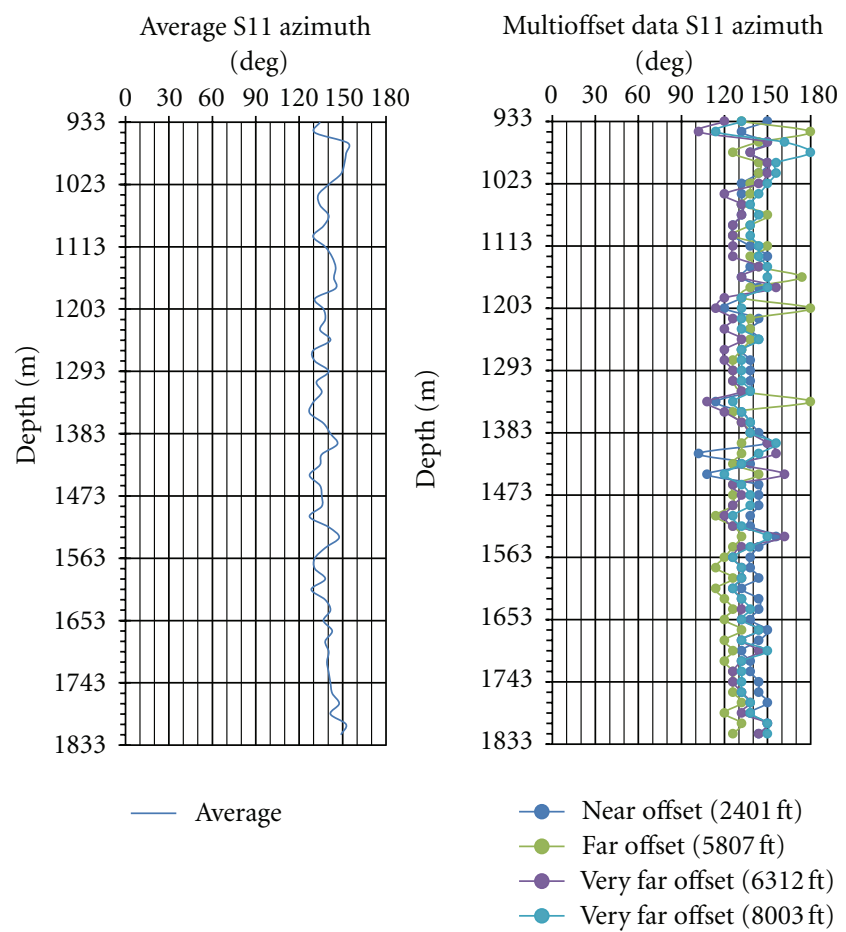

FIGURE 12: Shear VSP data with different source offsets (near-offset, mid-offset, and far-offset), using Alford rotation analysis, were analyzed.

transformation. A VSP-CDP transformation transforms VSP wave data from the depth-time domain to the offset-time domain [23]. This technique uses $2 \mathrm{D}$ ray tracing to map reflected signals into the offset-time domain [24]. After imaging the data using VSP-CDP transformation method, we calculated the fast shear wave RMS amplitude for a $30 \mathrm{~ms}$ window centered around the Morrow A sandstone (Figure 16).

\section{Results and Discussion}

Figures 15(c) and 15(d) compare the prestack zero-offset compressional and shear wave images as well as their corridor stacks. Although the Morrow A sandstone is visible on both datasets, it has higher amplitude when shear waves are used. It seems that the deconvolution filter has a considerable effect on compressional wave data and the Morrow A sandstone is not visible before applying this filter. Deconvolution filtering also assists us in resolving the Morrow A sandstone from the underlying layer in the shear wave data. Also, qualitatively, the zero-offset compressional and shear wave data have approximately the same temporal resolution.

Figure 16 displays the shear wave RMS amplitude map for a $30 \mathrm{~ms}$ window centered around the Morrow A sandstone from some shots on the northern part of the VSP well. Based on the Postle Field geology and the size of the high-amplitude areas, one hypothesis is that these features represent braid bars which are good quality and thick reservoir rocks. Also, the importance of the VSP data at this area is to map the edge of the channel (mainly NW$\mathrm{SE}$ at this part), and some linear features could show the evolution of the channel edge during time too. At the far

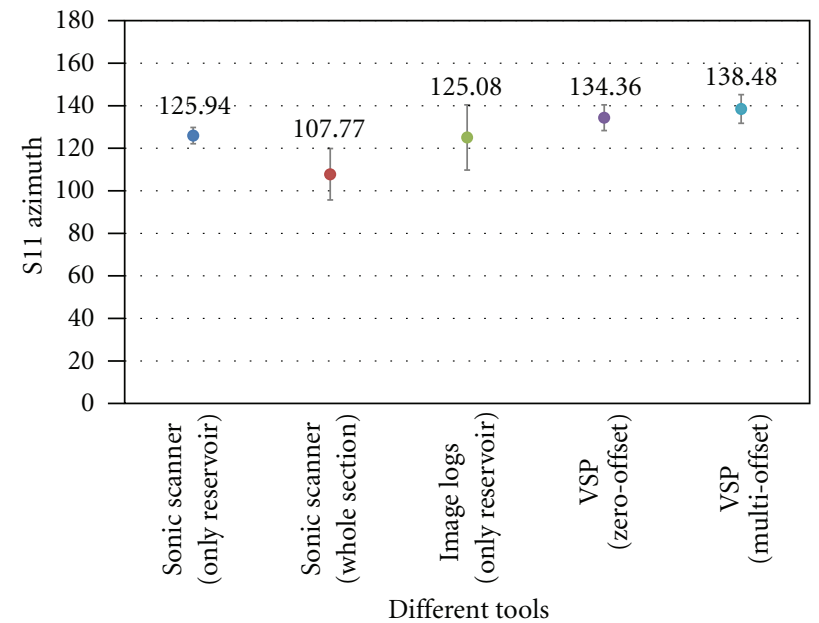

FIGURE 13: Fast shear wave polarization directions from different sources of information. The error bars indicate standard deviation of the estimated azimuths.

end of the map (data were recorded by geophones from 1 to 16 , located from $933 \mathrm{~m}$ to $1158 \mathrm{~m} \mathrm{MD}$ in the well), very high amplitude events could result from braid bars as well as strong noise (pay attention to arc shape of the high amplitude area). One reason for the high level of noise at this interval is a weak bond between the casing and the borehole wall. In addition, the presence of shale layers in the Morrow A sandstone can affect the RMS amplitude of the Morrow A. Some low-amplitude areas correspond to the presence of the mentioned shale layers and indicate low quality (or shaly sandstone) reservoir rocks. Unfortunately, as stated before, 


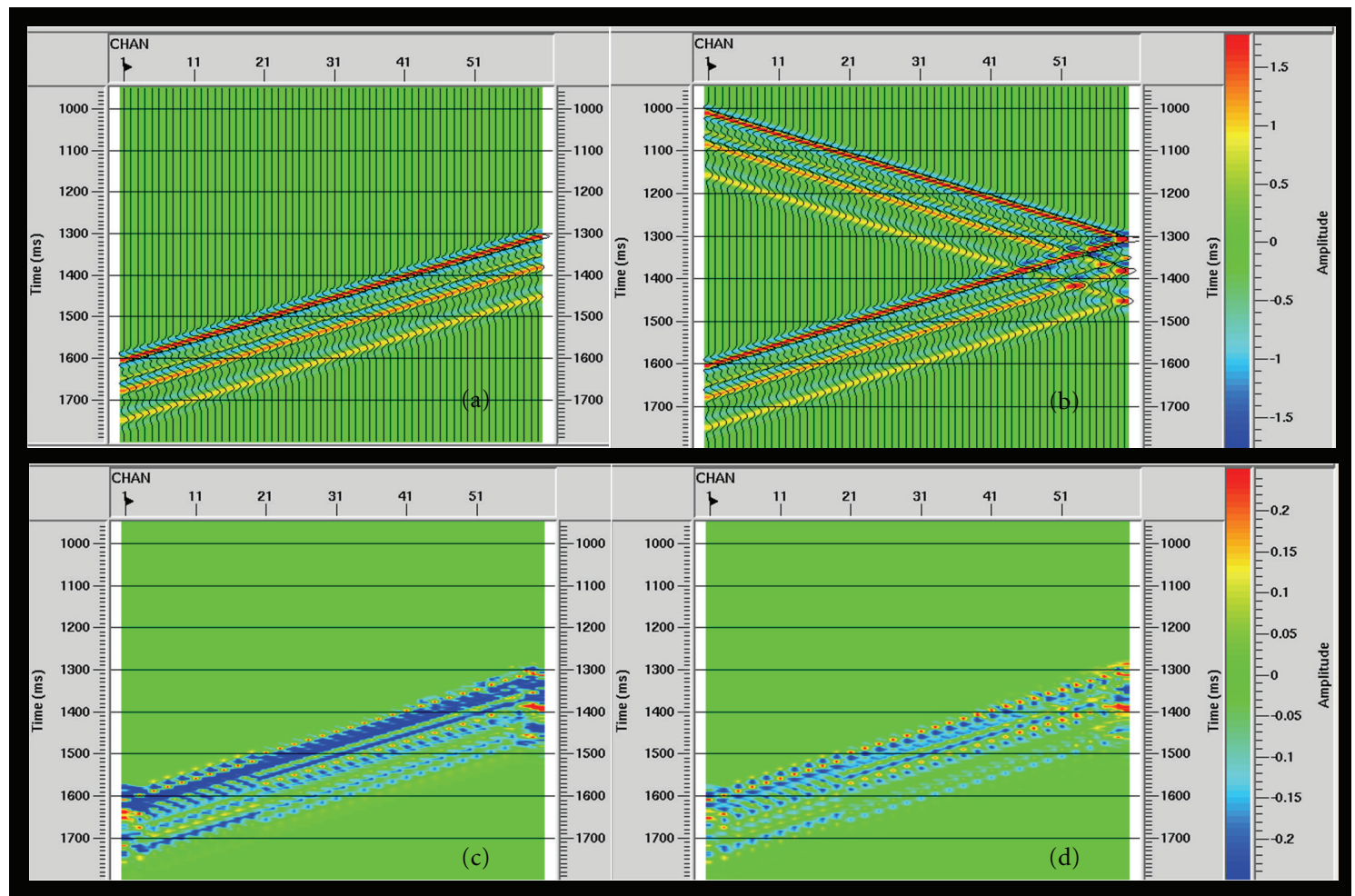

Figure 14: A synthetic zero-offset VSP shot gather was generated to compare the results after wavefield separation using median filter and dual median filter. (a) shows the synthetic upgoing wavefield, and (b) represents the synthetic zero-offset VSP shot gather after stacking with the downgoing wavefield. (c) and (d) depict the calculated residual amplitude (original upgoing wavefield-separated upgoing wavefield) after wavefield separation using median filter and dual median filter, respectively.

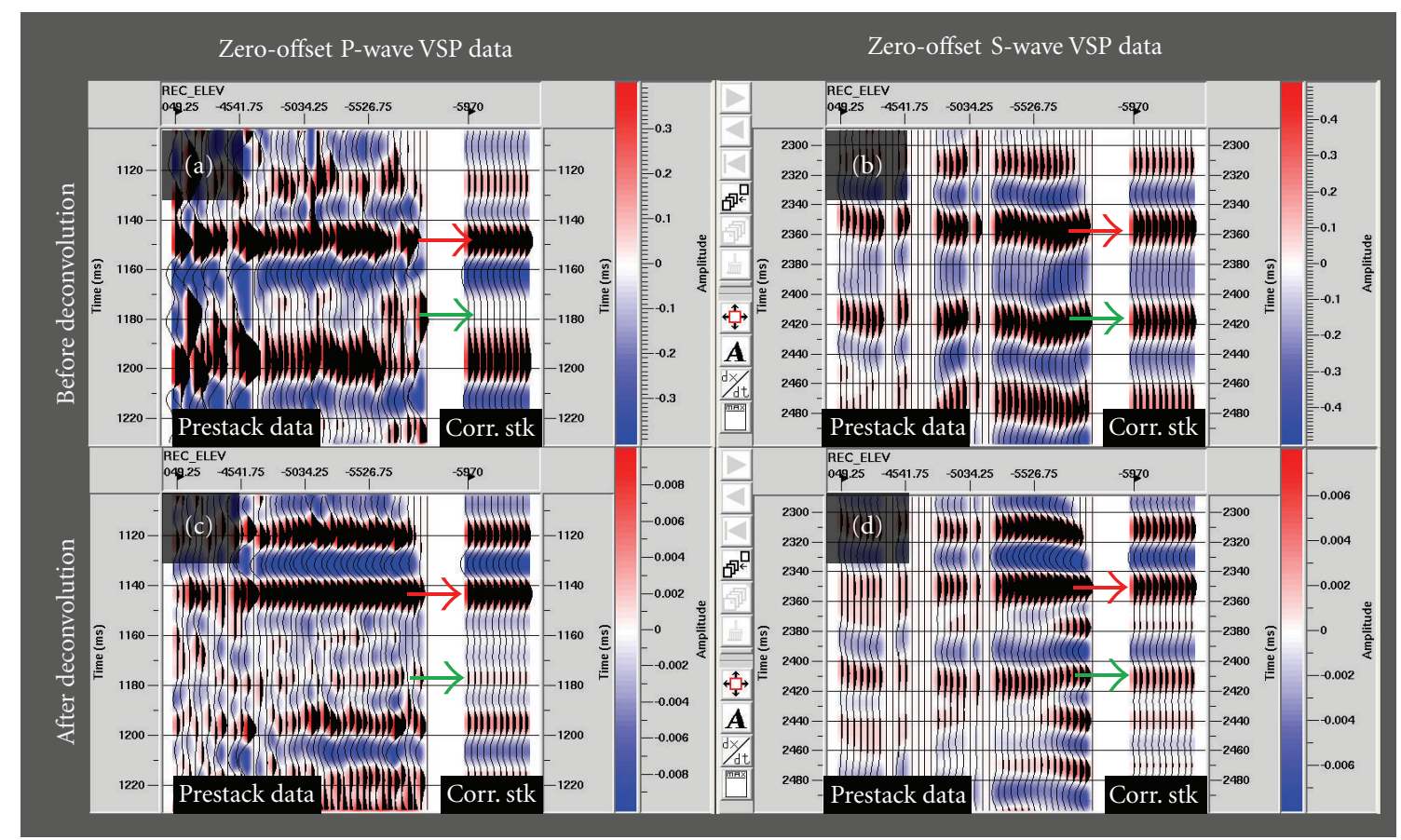

$\longrightarrow$ Atoka limestone

$\longrightarrow$ Morrow A sandstone

FIGURE 15: Zero-offset compressional (a) and (c) and shear (b) and (d) wave data before and after deconvolution. The green arrows show the Morrow A sandstone level, and the red arrows point to the Atoka limestone. Qualitatively, both datasets have similar temporal resolution, but the Morrow A event is more distinctive in the shear wave data than in the compressional wave data. 


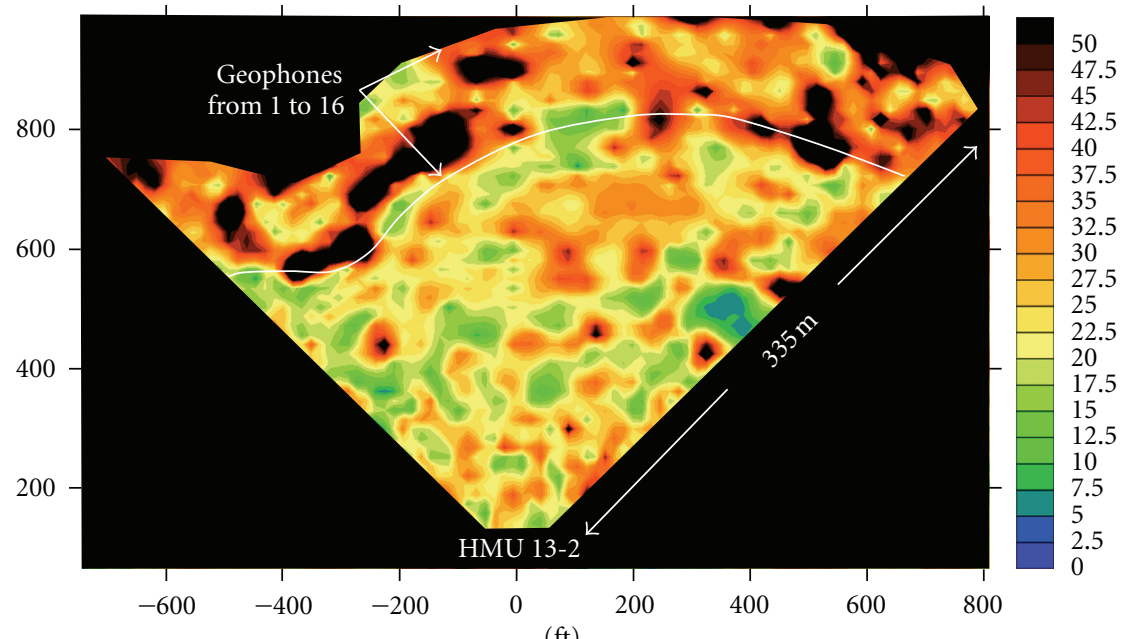

FIGURE 16: A 30 ms window centered around the Morrow A sandstone maps S11 RMS amplitude of the Morrow A sandstone on the northern part of the VSP well.

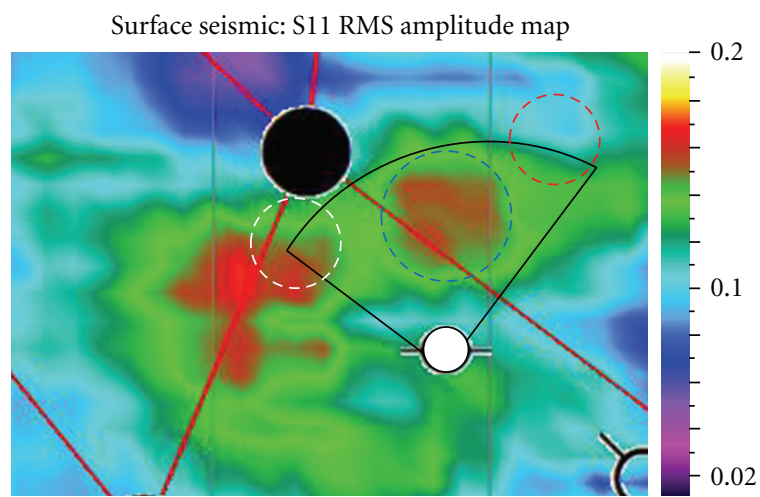

(a)

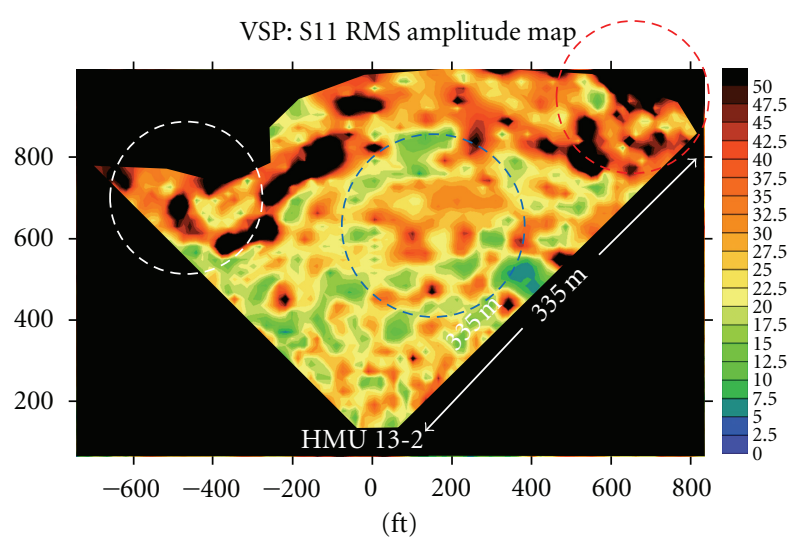

(b)

FIGURE 17: (a) S11 RMS amplitude map from the surface seismic data around well HMU 13-2. (b) S11 RMS amplitude map from the VSP data around well HMU 13-2. On both maps, there are two high-amplitude anomalies (white and blue circles). The white circle is on the edge of the VSP map where data are noisy and not reliable. But the blue circle highlights a coherent high amplitude area on both maps. The red circle shows high amplitude on the VSP data, but it is recognizable on the surface seismic data. Most likely, this high amplitude area (red circle) in the VSP data does not correspond to a geologic feature.

the data fold at this area is low and is the main limitation for the VSP image in this area. More 3D VSP coverage could image the Morrow A better and more reliably away from the VSP well.

Comparison of surface seismic and VSP RMS amplitude maps reveals advantages of the VSP data. Figures $17(\mathrm{a})$ and 17(b) represent the Morrow A sandstone S11 RMS amplitude map of the surface seismic (acquired on March 2008) and VSP data. Three amplitude anomalies are highlighted by circles showing similarities and differences between these two datasets. The most interesting anomaly is highlighted by blue circles on both images. The VSP data appear to map details better. The ability of the shear VSP data to delineate the extension of this anomaly reconfirms the advantages of the $\mathrm{S}$-wave VSP technique. As mentioned before, due to high heterogeneity in the reservoir, preserving original amplitudes and amplitudes variations is crucial. The ability of VSP data, after applying the proposed processing techniques in this paper, to delineate high-amplitude anomalies can reduce drilling risk.

\section{Conclusions}

Shear wave VSP data were processed using a modified processing flow. The main purposes of the proposed processing flow and some introduced techniques were to enhance the weak seismic response from the Morrow A sandstone in the presence of noise as well as to preserve amplitude variations caused by lithology changes (especially between the Morrow A sandstone and the Morrow shale). $3 \mathrm{C}$ amplitude analysis made VSP receiver reorientation more robust and avoided some processing artifacts. Also, estimating fast shear wave polarization direction using different tools addressed the scaling issue. The results of this analysis demonstrate that 
reliance on one source of information, either well logs or seismic data, can introduce significant uncertainty in final results. Dual median filtering was another method which was introduced to enhance VSP weak reflections where upgoing waves interfere with the strong downgoing waves.

Zero-offset VSP results reconfirmed the fact that the Morrow A sandstone signature is weak in compressional wave data. Also, it confirmed the ability of shear wave data to image the thin Morrow A sandstone. The Morrow A sandstone was mapped using the VSP-CDP transformation. High-amplitude anomalies in the shear wave RMS amplitude map could correspond to geologic features like braid bars, which fits the sediment deposition history of Postle Field. Comparison between surface seismic and VSP data showed the potential of VSP data in imaging detailed changes in subsurface rock properties and delineating anomalies with higher spatial resolution. Therefore, shear wave VSP data are able to map detailed geologic features where the heterogeneity in the Morrow A sandstone plays a major role.

\section{Acknowledgments}

The authors would like to acknowledge Tom Bratton from Schlumberger, Bruce Mattocks from CGGVeritas, and Richard Van Dok from HiPoint Reservoir Imaging for their advice. Also, they would like to thank their colleagues Dr. Robert Benson, Paritosh Singh, and Mohsen Minaei from RCP for their technical support. Special thanks to Whiting Petroleum for providing the multicomponent data. The authors would like to sincerely thank the Reservoir Characterization Project sponsors and students too.

\section{References}

[1] J. W. Benton, "Subsurface stratigraphic analysis, Morrow (Pennsylvanian), North Central Texas County, Oklahoma," The Shale Shaker Digest, vol. 21-23, pp. 21-23, 1973.

[2] D. C. Swanson, "Deltaic deposits in the Pennsylvanian upper Morrow formation of the Anadarko Basin, in Pennsylvanian sandstones of the mid-continent," Tulsa Geological Society Special Publication, no. 1, pp. 115-168, 1979.

[3] T. D. Jobe, Optimizing geo-cellular reservoir modeling in a braided river incised valley fill: postle field, Texas County, Oklahoma [M.S. thesis], Colorado School of Mines, 2010.

[4] J. R. Halverson, "Seismic expression of the Upper Morrow Sands in the Western Anadarko basin," Oil and Gas Journal, vol. 86, no. 44, pp. 290-303, 1988.

[5] J. T. Noah, R. D. Teague, and G. Hoand, "Twin Morrow field: a case study," The Leading Edge, vol. 13, p. 2530, 1994.

[6] M. L. Willey, Structural and stratigraphic controls on Morrow Sandstone reservoir distribution from 3-D seismic data, postle field, Texas County, Oklahoma [M.S. thesis], Colorado School of Mines, 2009.

[7] A. Robinson, Acoustic impedance inversion for static and dynamic characterization of a CO2 EOR Project, Postle Field, Oklahoma [M.S. thesis], Colorado School of Mines, 2010.

[8] M. Minaei and T. L. Davis, "Increasing seismic resolution by post-stack processing procedures in Postle Field, Oklahoma," in Proceedings of the 81st SEG Meeting, pp. 1036-1040, San Antonio, Tex, USA, 2011.
[9] T. L. Davis, R. D. Benson, S. Wehner, M. Raines, and R. Freidline, "Seismic reservoir characterization of the Morrow A Sandstone, Postle Field, Oklahoma," in Proceedings of the 80th SEG Meeting, pp. 2256-2260, Denver, Colo, USA, 2010.

[10] P. Singh and T. L. Davis, "Advantages of shear wave seismic in Morrow Sandstone detection," International Journal of Geophysics, vol. 2011, Article ID 958483, 16 pages, 2011.

[11] A. V. Wandler, T. L. Davis, and P. K. Singh, "An experimental and modeling study on the response to varying pore pressure and reservoir fluids in the Morrow A Sandstone," International Journal of Geophysics, vol. 2012, Article ID 726408, 17 pages, 2012.

[12] B. A. Hardage, M. DeAngelo, and P. Murray, "Defining P-wave and S-wave stratal surfaces with nine-component VSPs," The Leading Edge, vol. 22, no. 8, pp. 720-729, 2003.

[13] P. Mazumdar and T. L. Davis, "Shear-wave sourced 3-D VSP depth imaging of tight gas sandstones in rulison field, Colorado," CSEG Recorder, pp. 20-26, 2010.

[14] H. H. Hess, "Seismic anisotropy of the uppermost mantle under oceans," Nature, vol. 203, no. 4945, pp. 629-631, 1964.

[15] S. Crampin, "Evaluation of anisotropy by shear-wave splitting," Geophysics, vol. 50, no. 1, pp. 142-152, 1985.

[16] B. K. Sinha and S. Kostek, "Stress-induced azimuthal anisotropy in borehole flexural waves," Geophysics, vol. 61, no. 6, pp. 1899-1907, 1996.

[17] N. Tamimi, A. V. Wandler, and T. Bratton, "Processing and preliminary interpretation of full sonic waveform data, HMU 24-4, postle Oilfield," Reservoir Characterization Project Spring Meeting Report, pp. 46-53, 2009.

[18] B. S. Aadnøy and J. S. Bell, "Classification of drilling-induced fractures and their relationship to in-situ stress directions," $\log$ Analyst, vol. 39, no. 6, pp. 27-40, 1998.

[19] M. P. Harrison, Processing of P-SV surface seismic data: anisotropy analysis, dip moveout, and migration [Ph.D. dissertation], University of Calgary, 1992.

[20] R. M. Alford, "Shear wave data in the presence of azimuthal anisotropy," in Proceedings of the 56th SEG Meeting, pp. 476479, Dilley, Tex, USA, 1986.

[21] Z. Sun and M. J. Jones, "VSP multi-algorithm shear-wave anisotropy study," CREWES Research Report, vol. 5, pp. 601$622,1993$.

[22] J. H. Kommedal and B. A. Tjostheim, "A study of different methods of wavefield separation for application to VSP data," Geophysical Prospecting, vol. 37, no. 2, pp. 117-142, 1989.

[23] K. D. Wyatt and S. B. Wyatt, "Determining subsurface structure using the vertical seismic profile," in Vertical Seismic Profiling, Part B-Advanced Concepts, N. M. Toksoz and R.R. Stewart, Eds., Geophysical Press, 1984.

[24] S. J. Gulati, R. R. Stewart, J. Peron, and J. M. Parkin, "3C-3D VSP: normal moveout correction and VSPCDP transformation," CREWES Research Report, vol. 9, pp. 901-930, 1997. 

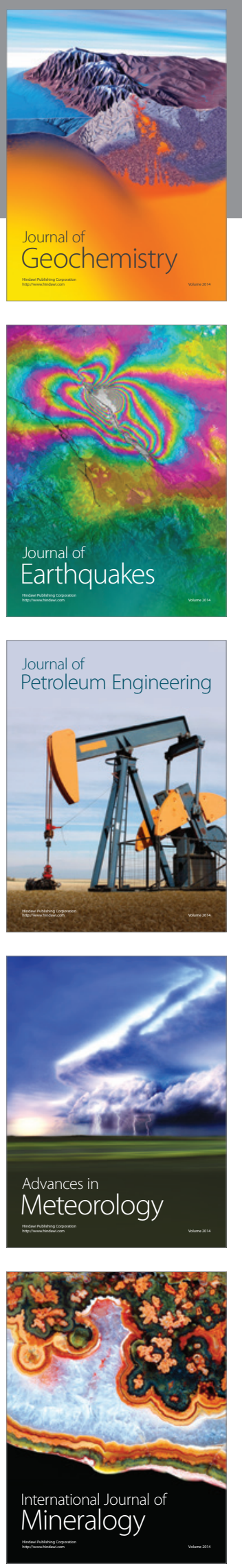
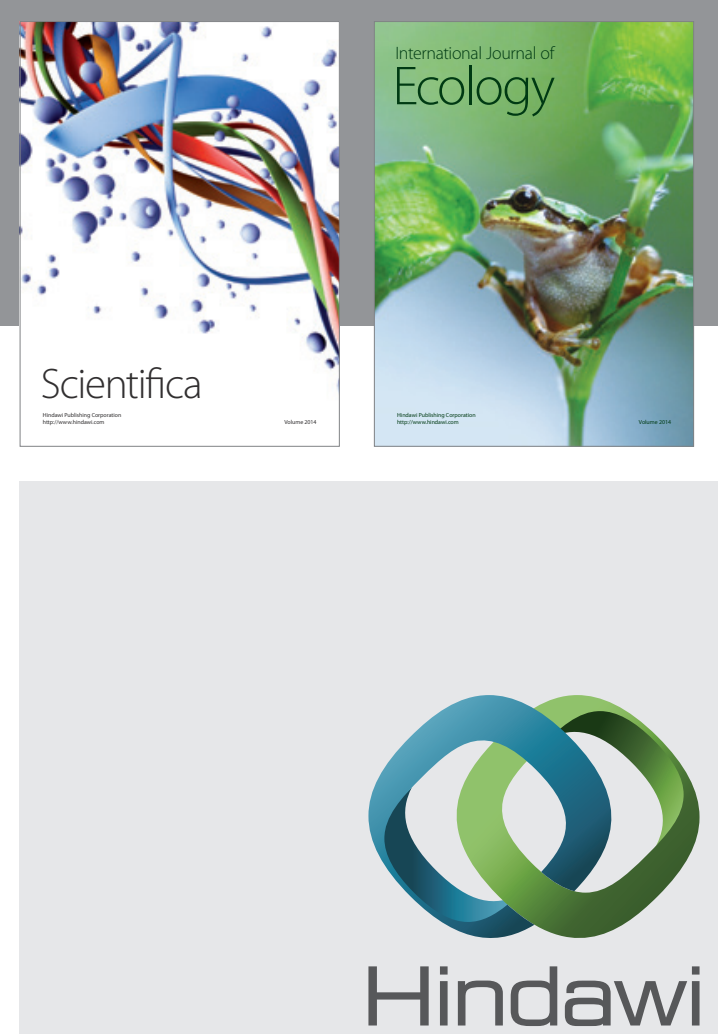

Submit your manuscripts at http://www.hindawi.com
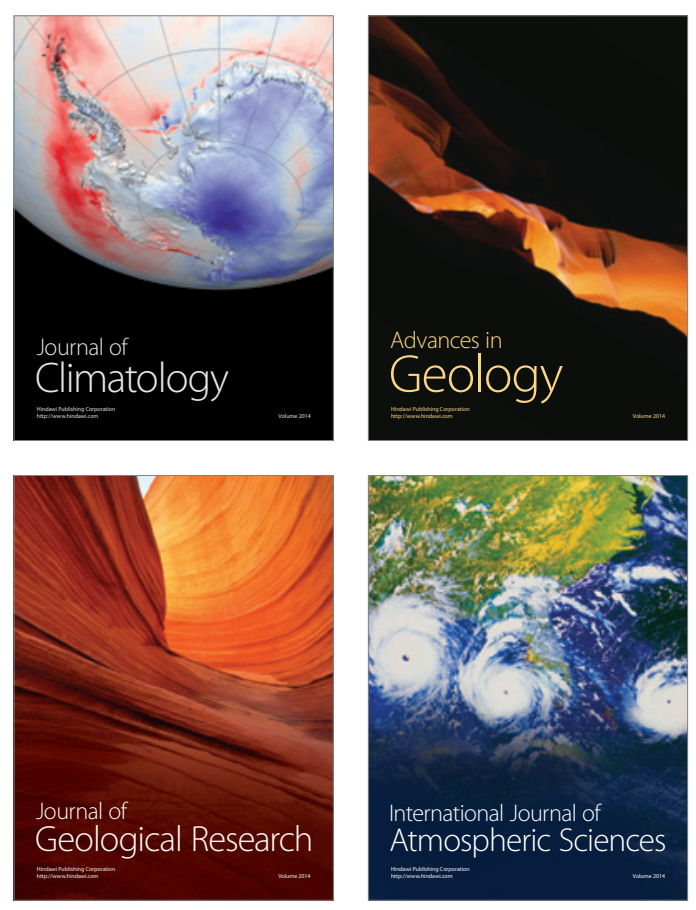
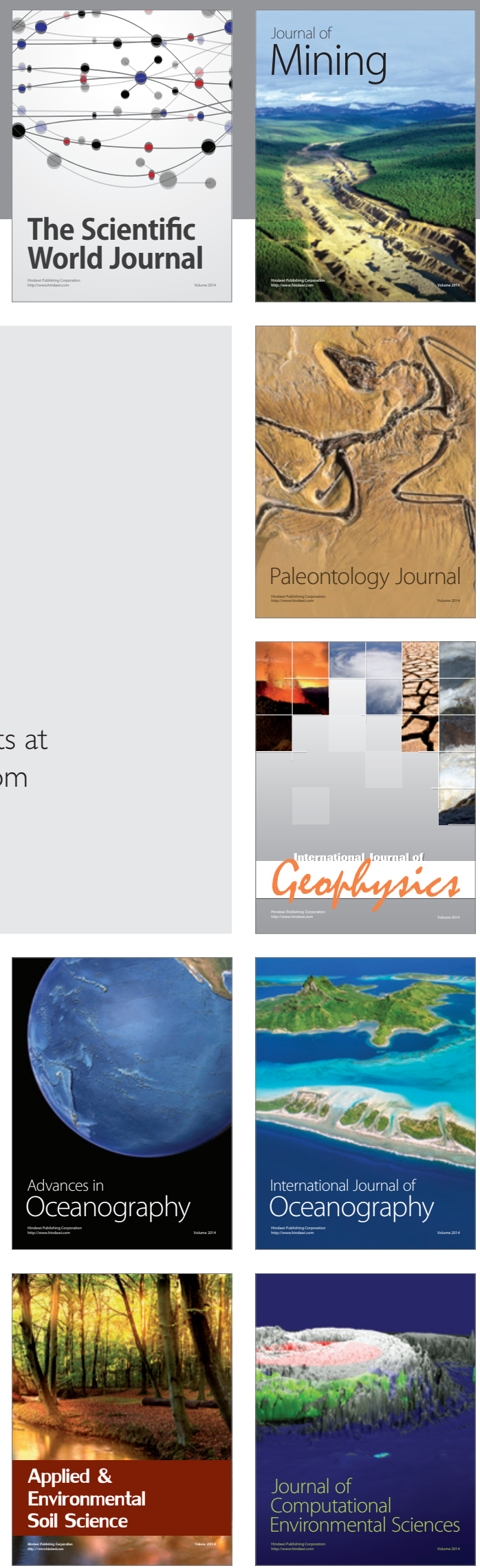